\title{
EL CINE EN LA PASTORAL DE LAS VOCACIONES
}

\author{
EMILIO LAVANIEGOS - JUAN FRANCISCO COMENDADOR ${ }^{1}$
}

DOI: https://doi.org/10.52039/seminarios.v54i188.535

Los autores que han publicado un libro sobre el tema² nos regalan en este artículo una síntesis completa, bien descrita y práctica. Utilizan un lenguaje pedagógico encomiable que nos va guiando a lo largo del artículo de lo general a lo particular, del concepto a la experiencia, de lo razonable a lo imaginable. Seguramente para desarrollar la última propuesta La escena peregrina, haga falta afición cordial (y actual) al cine, conocimiento del medio, intuición en el alcance y creatividad asolada. Todo un reto. Pero de eso se trata en esta revista de teología y pastoral de las vocaciones y los ministerios. No se trata de dar recetas sino de motivar un determinado estilo de trabajo y sacar lo mejor de uno mismo en la misión del trabajo por las vocaciones y con las vocaciones. ¡Ánimo a los creativos!

Introducción.- 1. El cine como medio de comunicación (74); 2. El cine como medio de comunicación de la fe (79); 3. ¿Y el cine en la pastoral de las vocaciones? (82); 4. Condiciones para usar una película en la pastoral de las vocaciones (83); 5 . Dos géneros vocacionales (85); 5.1. Género vocacional épico (85); 5.2. Género vocacional contemporáneo (86); 6 . Tres propuestas para utilizar el cine en la pastoral de las vocaciones (88); 6.1. El cine foro clásico (89); 6.2. La escena vocacional (90); 6.3. La escena peregrina (90).

\footnotetext{
${ }^{1}$ Los autores han estado dos años formando equipo en el instituto de pastoral vocacional de México: ANIMACIÓN VOCACIONAL SOL. Ambos Sacerdotes Operarios. Ambos, desde la postmodernidad, empeñados en hacer posible un lenguaje que transmita los valores vocacionales y la dinámica gratuita de la vocación. Emilio Lavaniegos, mexicano de la ciudad de México, sacerdote desde 1988, veinte años de sacerdote. Juan Francisco Comendador de La Villa de Don Fadrique, en la Mancha toledana, sacerdote desde 2008, unos meses de sacerdote. ¡Un lujo de compañeros! 2 La Vocación en el Cine. Selección de películas para la pastoral vocacional. Animación Vocacional Sol, 164 páginas, 11,50 \$.
} 
En la mente de los evangelizadores arraiga cada día más la convicción de que es necesario buscar nuevas formas para transmitir la buena noticia de Jesús. Al mismo tiempo ha crecido la sensibilidad de los mismos para captar las semillas del verbo que de alguna manera están esparcidas en las diversas culturas. Ambas convicciones conducen a un diálogo con la cultura que ha de ponerse en práctica prescindiendo de un lenguaje teológico, apenas comprensible para la mayoría de la gente, y utilizando el lenguaje corriente propio de esas culturas. Uno de estos lenguajes, quizá el más evocador de la realidad en la que permanece vivo el evangelio, es el cine.

Es difícil ofrecer una definición de lo que es el cine. Sin duda, es preciso considerarlo desde un punto de vista técnico: un complejo proceso que va desde la elaboración de un guión hasta el montaje final en el que intervienen una pléyade de profesionales, desde los actores hasta los productores. Pero una película es también una obra de arte, una expresión cultural, pues se trata de una creación humana que da respuesta a los problemas e inquietudes fundamentales del ser humano. Además, es un producto comercial, un bien de consumo al que se accede a través del mercado.

Queremos acercarnos al cine como un medio de comunicación. No pretendemos, por tanto, valorar el cine refiriéndonos a criterios técnicos, culturales o mercantiles, sino ateniéndonos a su potencial comunicativo, a su ingente capacidad evocadora. La magia del cine consiste en eso: una película nos cautiva y emociona cuando logra establecer la comunicación con el complejo mundo de emociones y sentimientos que llevamos dentro.

Adoptamos esta perspectiva -entender el cine como medio de comunicación- porque lo que proponemos es aprovechar el caudal comunicativo que las películas contienen para transmitir diversos mensajes en torno a la vocación.

\section{El cine como medio de comunicación}

La comunicación es un fenómeno típicamente humano. Cuando afirmamos que los animales se comunican, lo decimos por analogía con la comunicación humana. Lo distintivo de ésta es la intencionalidad, es decir, la decidida resolución de informar algo acerca de nosotros mismos o las circunstancias que nos rodean.

Comunicar no es lo mismo que informar. Mientras la información viene definida por la referencia a datos objetivos, la comunicación -en el sentido humano y personal del término- exige una persona que se involucra, se 


\section{SEMINARIOS - AÑO 2008 - NO 188 \\ EL CINE EN LA PASTORAL DE LAS VOCACIONES, E. LAVANIEGOS Y J. F. COMENDADOR}

compromete. Así, hablamos de distintos niveles de comunicación para dar cuenta de la diferencia entre una información superficial y un desvelamiento de nuestro yo. No es lo mismo comentar el estado del tiempo -iqué calor hace!- que mostrar un estado de ánimo -me siento triste-. Mientras que en la primera afirmación estamos informando de algo objetivo, el clima, en la última estamos comunicando algo personal, un sentimiento.

La información se caracteriza además por la relevancia de la palabra, del lenguaje verbal. La comunicación, en cambio, exige otros códigos comunicativos o lenguajes para ser tal. No sólo nos comunicamos verbalmente, sino que también lo hacemos a través de nuestro cuerpo, de la postura que adoptamos, de la posición de las extremidades, de las facciones del rostro, etc. Podemos decir, pues, que la comunicación es audiovisual por naturaleza, es decir, se produce a través de distintos canales o lenguajes (la palabra, el cuerpo, el contexto, la luminosidad, los sonidos, etc.) que coadyuvan a que ésta se produzca. Si faltase alguno de estos canales, la comunicación resultaría incompleta. No es lo mismo, por ejemplo, hablar con un buen amigo por teléfono que cara a cara. A través del teléfono oigo su voz, pero no puedo ver su mirada, sus gestos faciales, la posición de sus manos, etc.

Grosso modo podemos decir que a través de la palabra obtenemos el contenido racional de la comunicación y a través de la imagen el contenido emocional ${ }^{3}$. Esto se aprecia claramente cuando se da incongruencia entre ambos códigos. Si, por ejemplo, alguien me dice que está contento con lágrimas en los ojos y el rostro cariacontecido, seguramente no le creeré. Existe una divergencia entre lo que pretende comunicarme por la palabra y lo que realmente me comunica a través de su rostro. Incluso mediante el tono de voz puedo vislumbrar la incoherencia entre el significado objetivo de las palabras y el modo de pronunciarlas (sin entusiasmo, con pesadumbre).

El potencial arrebatador del cine se explica por la nitidez con que se perciben ambos tipos de códigos, el de la palabra y el de la imagen. En una pantalla de cine es posible captar detalles que en la vida real pasarían desapercibidos, tanto en la imagen como en el sonido. Una huella sobre el barro, el sonido de unos pasos, el humo de un cigarro, etc., pueden ser apreciados de un modo más palmario que en la realidad. Podemos decir que en el cine hay menos interferencias en la comunicación, el lenguaje audiovisual es captado con mayor claridad por el receptor.

3 Véase al respecto el capítulo Sentir es lo primero, en BABIN, P., El lenguaje de la nueva cultura, San Pablo, Madrid, 1993, pp. 11-35. 
El sonido completa, modula y esclarece el sentido de la comunicación, pero la piedra angular sobre la que ésta se sustenta es la imagen. Existe un tipo de cine sin sonido -el cine mudo-, pero es inconcebible un cine sin imagen. Si esto es así, queda claro entonces que el lenguaje principal del cine es de índole emocional. En efecto, las películas utilizan un código comunicativo donde los sentimientos y las emociones adquieren todo el protagonismo. La primera valoración que hacemos de una película se atiene al sentimiento general provocado en nosotros: me gustó o no me gustó. Sólo en un segundo momento matizamos este primer juicio considerando otros puntos de vista como la interpretación de los actores o el interés de la problemática planteada.

Hablar del lenguaje emocional del cine supone considerar la relación que se establece entre una película y el espectador como una comunicación, como un diálogo o conversación. Todo lo dicho hasta ahora se asienta sobre esta metáfora. Desde esta perspectiva, lo importante no es la cualidad objetiva de la película en cuestión, sino el producto de la interacción entre película y espectador. Así, una película puede ser técnicamente buena, bien hecha, pero quizá no transmita el mensaje que se ha propuesto comunicar.

Esta distinción entre lo técnico y lo comunicativo nos ayuda a comprender las razones por las que películas que parecían destinadas al fracaso, adquieren por el contrario un gran éxito comercial y viceversa. Pongamos un ejemplo reciente. Durante las fiestas navideñas de 2006 se estrenó El Nacimiento (Catherine Hardwicke), enésima puesta en escena del nacimiento de Jesús y los célebres acontecimientos sucedidos en torno al mismo (anunciación, huida a Egipto, adoración de los magos, etc.). La película se anunció a bombo y platillo como la versión histórica de los extraordinarios acontecimientos que celebramos en la Navidad, pero prácticamente pasó desapercibida por las salas de cine. La razón de esto no hay que buscarla en su poca valía cinematográfica, sino más bien en la escasa impresión que el guión y la puesta en escena causaban en el espectador. En efecto, el nacimiento de Jesús tiene un significado profundo para los creyentes, de tal modo que la mera descripción de los hechos acaecidos no respeta las expectativas del espectador creyente. Un filme que aborda esta temática tan claramente religiosa ha de cumplir una función mistagógica, es decir, ha de remitir al misterio, al significado profundo de los hechos allí narrados. En otras palabras: la película estaba bien hecha desde un punto de vista técnico, incluso con llamativos efectos especiales, la interpretación de los actores era aceptable; pero el significado propuesto bajo tal significante de imagen y sonido no encontró eco en los espectadores. Es en esta resonancia donde estriba el éxito de una película. 


\section{SEMINARIOS - AÑO 2008 - NO 188 \\ EL CINE EN LA PASTORAL DE LAS VOCACIONES, E. LAVANIEGOS Y J. F. COMENDADOR}

Asumir la preponderancia del lenguaje emocional sobre otros, la capacidad del cine de evocar, de zarandear el corazón haciéndonos experimentar las más variadas emociones, no significa otorgar a este código lingüístico la exclusividad en la comunicación cinematográfica. El cine también comunica a través de las palabras, de los diálogos, los silencios...; es decir, comunica mediante un lenguaje que podemos llamar lógico o racional. Las películas no sólo nos hacen llorar o reír, sino que también nos hacen pensar, nos muestran realidades desconocidas, nos provocan interrogantes, nos proponen respuestas, etc.

Hay muchas películas cuyo principal interés no radica en el efecto emocional causado en el espectador, sino en la historia que narran, en el problema que, por decirlo así, se pone sobre la mesa. En este tipo de películas predomina el código racional sobre el emocional. Pero, como hemos afirmado para el caso contrario, este predominio no conlleva exclusión; de hecho, en estas películas el lenguaje racional se reviste de emociones para asegurarse el éxito de la comunicación:

Muchas películas han servido de acicate para hacer explícita alguna cuestión social, para generar un debate público sobre determinados temas o para reflejar posturas estereotipadas sobre diversos asuntos de interés para la sociedad. Es el caso, por ejemplo, de Philadelphia (Jonhatan Demme, 1993), película protagonizada por Tom Hanks que suscitó un amplio debate en torno a la relación entre homosexualidad y la enfermedad del sida. O el de Pena de Muerte (Tim Robbins, 1995), protagonizada por Susan Sarandon y Sean Penn, que se hacía eco de la preocupación ética de la sociedad estadounidense en torno a la pena capital. Son películas que hacen pensar y que toman partido por una respuesta posible al problema planteado utilizando para ello el lenguaje emocional: tocan el corazón del espectador provocando su solidaridad con la causa del protagonista.

Para que se produzca la comunicación se requiere la presencia de al menos dos interlocutores. Hasta ahora hemos mencionado diversos elementos relativos a la película como elemento emisor, pero, ¿qué ocurre con el espectador? ¿Cuál es su papel en la comunicación? Es obvio que la película interviene activamente en el proceso comunicativo proponiendo un mensaje, pero ¿y el espectador? ¿qué aporta el espectador a la comunicación?

Podemos afirmar que el espectador es un agente directo de la comunicación al menos en dos sentidos. En primer lugar, construye la comunicación con su sola presencia, pues sin ésta la película quedaría, digámoslo así, muda. De alguna forma, la presencia del espectador se torna en condición de posibilidad de la comunicación cinematográfica. En otras palabras: una película que no es vista no existe (para nadie). 
Pero su intervención en el proceso comunicativo no se reduce a la mera contemplación, esto es, no juega un papel pasivo, sino que contribuye singularmente a la construcción de la comunicación. El espectador que contempla una película no es una tabula rasa, un recipiente vacío que asimila acríticamente cualquier información. El espectador posee un carácter único, una peculiar trayectoria de vida y un singular bagaje de conocimientos y emociones. Todo ello constituye su aportación al proceso comunicativo. Y lo hace de dos maneras en función del doble tipo de lenguaje que sustenta la comunicación cinematográfica:

* A un nivel emocional. El espectador reacciona a los estímulos de la imagen de una determinada manera en función de su memoria afectiva, de su particular gramática emocional. Podré sentir compasión de algún personaje si he experimentado con anterioridad en la vida real este sentimiento. Podré meterme en la piel del protagonista que se enamora si alguna vez me he enamorado. Nuestra experiencia sentimental, por así decirlo, determina la reacción emocional derivada de la contemplación de una película.

Hace unos años fui al cine con un amigo a ver la película Mi vida sin mí (Isabel Coixet, 2003). La película versa sobre una joven madre a quien le diagnostican un cáncer. Consciente de que la enfermedad es irreversible, decide ocultar el diagnóstico a su pareja e hijos, tratando de dejar los cabos atados para que estos puedan sobrellevar su ausencia de la mejor manera posible. No hacía más de tres meses que mi amigo había perdido a su padre, quien había muerto relativamente joven víctima de un cáncer de efectos fulminantes. A la salida del cine, mi amigo se encontraba profundamente conmocionado y comenzó a llorar durante un largo rato. La película había despertado en él unos sentimientos y emociones que distaban de parecerse a los que había suscitado en mí. Cada uno, desde nuestro peculiar bagaje sentimental, tuvimos una comunicación diferente con el filme.

* A un nivel lógico o racional. El espectador que contempla una película que aborda, por ejemplo, un tema de carácter social, posee unos prejuicios en torno a dicho tema; es decir, tiene una opinión al respecto, aunque no esté explícitamente formulada. Del mismo modo, si por las razones que sean, el asunto es desconocido o carece de interés para mí, o no estoy preparado para comprenderlo, difícilmente puede darse una comunicación completa entre la película y yo. Los prejuicios con que yo observo una cuestión determinan mi capacidad para captar la propuesta que la película me hace en torno a tal cuestión.

Fui a ver la película Mar Adentro, de Alejandro Amenábar (2004), con un grupo de adolescentes a los que preparaba para que recibiesen el 


\section{SEMINARIOS - AÑO 2008 - NO 188 \\ EL CINE EN LA PASTORAL DE LAS VOCACIONES, E. LAVANIEGOS Y J. F. COMENDADOR}

sacramento de la Confirmación. La película, basada en hechos reales, cuenta la historia de Ramón Sampedro, un tetrapléjico que decidió poner fin a su vida ante la imposibilidad de llevar, a su juicio, una vida digna. La película, que reavivó el debate en torno a la eutanasia en la sociedad española, tomaba clara postura a favor de la misma. Después del cine dimos un paseo y comentamos qué nos había parecido la película. Mi sorpresa y escándalo fueron mayúsculos al constatar que la mayoría se declaraba a favor de la eutanasia. De nada me valieron los argumentos referentes a las implicaciones éticas de esta, ni mucho menos las consideraciones teológicas acerca de la vida como don de Dios. El prejuicio de los muchachos era el siguiente: Cada uno con su vida hace lo que quiere. El mío era más específico: la eutanasia es un atentado contra la vida. Su motivación para ver la película era pasar un buen rato. La mía, en cambio, era tener noticia del modo en que este filme planteaba el controvertido asunto. Nuestros prejuicios, nuestras percepciones e intereses previos, determinaron por completo el mensaje transmitido en la comunicación cinematográfica.

Hemos definido la relación entre película y espectador como comunicación. Se trata de un proceso en el cual tanto la película como el espectador intervienen activamente: la primera proponiendo un mensaje y provocando una experiencia, el espectador reaccionando ante el estímulo y adoptando una postura.

\section{El cine como medio de comunicación de la fe}

La comprensión del cine como un medio de comunicación ha llevado a muchos creadores y pensadores cristianos a hacerse la siguiente pregunta: ¿se puede comunicar la fe a través del cine? Si esto es posible, ¿de qué manera?

No es nuestro propósito teorizar en este espacio sobre la posibilidad o imposibilidad de comunicar la fe a través del cine. Partimos del hecho de que, al margen del éxito obtenido, tal empresa ya se ha acometido; es decir, existen películas cuya intención explícita ha sido comunicar la fe. Desde la épica Rey de Reyes (George Stevens, 1961) hasta la más reciente La Pasión (Mel Gibson, 2004) han sido muchas las películas realizadas que se incluyen en el denominado género religioso. Se considera a una película como perteneciente a este género cuando tiene su fundamento en la Biblia, o cuando se trata de hagiografías, o cuando la Trascendencia y lo sagrado juegan un papel relevante, o cuando se resalta algún acontecimiento de la historia del cristianismo, etc. 
Algunas películas clásicas de este género son Los diez mandamientos (Cecile B. DeMille, 1956), El Evangelio según san Mateo (Pasolini, 1964), La historia más grande jamás contada (Nicholas Ray, 1965), Jesús de Nazareth (Zefirelli, 1977), Jesucristo Superstar (Norman Jewison, 1973), La última tentación de Cristo (Martin Scorsese, 1988), La Pasión (Mel Gibson, 2004). Sobre Juana de Arco y Francisco de Asís se han hecho varias películas, aunque las más recientes y de mayor éxito son Hermano Sol, Hermana Luna (Franco Zefirelli, 1973) y Juana de Arco (Luc Besson, 1999). También ha sido llevada al cine la biografía de personajes como Lutero (Eric Till, 2003) o Gandhi (Richard Attenborough, 1982)4.

Ahora bien, no todas las películas de género religioso han sido creadas con la intención manifiesta de comunicar la fe. A muchos creadores les ha movido más el interés histórico por algún personaje o evento que el afán evangelizador. Del mismo modo, películas que no se incluyen en el género religioso han surgido de interrogantes existenciales de sus creadores o abordan explícitamente la cuestión de la fe o la apertura a la trascendencia.

En todo caso, lo que a nosotros nos interesa no es si tal o cual película ha de ser considerada como perteneciente al género religioso, sino que nos interesan estos filmes en la medida en que establecen una comunicación de fe con el espectador 5 . Por ejemplo, La última tentación de Cristo, de Martin Scorsese, no tiene una intención evangelizadora. Sin embargo, a pesar de esto, hay escenas conmovedoras que presentan rasgos del Jesús histórico que invitan al seguimiento.

Seguramente hemos utilizado este tipo de cine para ilustrar sobre la vida de Cristo o para dar a conocer los episodios más relevantes de la Historia Sagrada en diversos ámbitos: durante unas misiones de Semana Santa o unos ejercicios espirituales, en una convivencia o retiro, en un encuentro de catequesis, en una clase de educación en la fe, etc. Es frecuente, por ejemplo, encontrar fotogramas de estos filmes insertos en power points catequéticos.

Pero no es esta la única manera en que el cine se pone al servicio de una comunicación de fe. También el cine se utiliza en la catequesis para transmitir valores cristianos. Para ello se usan películas con mensaje o de valores. La metodología habitual de este uso consiste en ver la película en

\footnotetext{
4 GIL DE MURO, E. (dir), Diccionario de Jesús en el cine, Ed. Monte Carmelo, Burgos, 2006.

5 RODRIGUEZ PANIZO, P., Hacia una teología del cine, Ed. Sal Terrae, Santander, 2001, pp. 12-32.
} 


\section{SEMINARIOS - AÑO 2008 - NO 188 \\ EL CINE EN LA PASTORAL DE LAS VOCACIONES, E. LAVANIEGOS Y J. F. COMENDADOR}

cuestión y después comentarla. Es lo que conocemos con el nombre de cineforo ${ }^{6}$.

Los supuestos sobre los que se asienta esta práctica han quedado explicitados en el punto anterior. Habría que añadir dos, de alguna manera ya insinuados. Por parte de la película, se exige que su mensaje global sea positivo, planteando algún problema humano, proponiendo algún valor cristiano y ofreciendo una salida auténtica al problema. Por parte del espectador se exige una actitud crítica, o sea, ser capaz de contemplar la película tomando la distancia necesaria para vislumbrar la problemática planteada y juzgar la solución respectiva que la película propone.

El cineforo es un medio de análisis del cine que pone su atención a diversos aspectos: la estética, la técnica, la congruencia del guión, etc. Es decir, no es una práctica que haya surgido con un interés catequético. Sólo en un segundo momento se pasa del análisis de la película en su totalidad a la consideración de su mensaje con fines educativos. Así, el cineforo pastoral o catequético rescata sobre todo el lenguaje lógico o racional de la película.

Lo interesante de la metodología del cineforo es que se parte de una situación humana para desde ahí ofrecer una respuesta de fe. Se muestra así que la fe no es algo abstracto y sin incidencia en la vida, sino que ha de traducirse en comportamientos concretos. Un cineforo no debe quedarse sólo en el diálogo, sino que ha de conducir al compromiso personal. Si vemos una película donde se propone el valor cristiano de la solidaridad, el diálogo posterior debiera concluir preguntándonos por la manera en que yo, aquí y ahora, puedo poner en práctica dicho valor. El cineforo pastoral o catequético es a veces general o inespecífico: se centra en un valor que se propone como bueno para regir la propia vida (generosidad, solidaridad, sacrificio de sí, etc.). Otras veces se centra en problemas específicos, utilizando la película como excusa para exponer la postura cristiana sobre el tema en cuestión (eutanasia, aborto, pena de muerte, homosexualidad, etc.). Hay que decir, sin embargo, que estas cuestiones -quizá por cansancio- interesan poco a la gente o son irrelevantes para los participantes.

A pesar de la aparición de nuevos recursos (internet, power points, cds interactivos, etc.), el cine seguirá sirviendo como herramienta pastoral en la medida en que constituye un lenguaje propio y está presente en la cultura. Desde sus inicios el cine ha sido acicate para la reflexión, ha denunciado

6 Una explicación asequible acerca de la historia, valores y modelos de aplicación del cineforo se encuentra en CAMPOS MARTíNEZ, L., Cineforo. Interpretación grupal del filme. Ed. Paulinas, Bogotá, 1989. 
aspectos de la sociedad, ha propuesto modelos de vida, etc. En la medida en que el cine continúe ejerciendo el rol que actualmente ocupa en el espacio cultural, continuará siendo un instrumento imprescindible para comunicar los contenidos de la fe cristiana.

\section{3. ¿Y el cine en la pastoral de las vocaciones?}

¿Qué decir, en concreto, del uso del cine en la pastoral de las vocaciones? ¿Se utiliza esta herramienta? ¿De qué manera? Probablemente existen diversas respuestas a estos interrogantes en función de la particular sensibilidad cinematográfica de cada agente de pastoral de las vocaciones. En todo caso, lo que hemos afirmado respecto al uso del cine como medio de comunicación de la fe debe aplicarse por igual al mensaje de la vocación, que es un contenido fundamental de la fe cristiana.

El cine religioso ha presentado con diversidad de matices algunos episodios vocacionales significativos, aunque siempre como un momento más de la trama. Las películas sobre Jesús o sobre otros personajes como Ghandi, Lutero o Francisco de Asís incluyen el descubrimiento de la vocación como un momento necesario del guión. Ese momento sucede de diversas maneras, aunque no siempre se explicite como tal.

De igual forma que otros géneros de cine distintos al religioso han sido utilizados en la catequesis para presentar valores cristianos, ese mismo tipo de cine puede utilizarse para introducir valores específicamente vocacionales. Será difícil dar con una película que muestre en toda su amplitud significativa el concepto auténtico de vocación. Pero no se trata de que el filme explique todo, de que sea explícito sobre la cuestión vocacional, sino de que transmita algunos rasgos o indicios acerca de ésta que nos permitan cimentar sobre ella una catequesis vocacional.

En el capítulo siguiente proponemos tres modos de llevar a cabo un cineforo vocacional, en función de las características de la película. En él sugerimos algunos requisitos o condiciones que ha de reunir un filme para que pueda utilizarse en la catequesis vocacional. Pero antes de seguir adelante es preciso hacer un par de aclaraciones.

Cuando hablamos de pastoral de las vocaciones, no nos estamos refiriendo exclusivamente al momento de la toma de conciencia de la vocación. Con frecuencia, los promotores vocacionales sólo han atendido este momento privilegiado en la vida de las personas, descuidando las etapas previas y, por supuesto, las posteriores, consideradas competencia de los formadores y los superiores. La concepción de pastoral de las vocaciones que subyace a nuestra propuesta tiene en cuenta diversas 


\section{SEMINARIOS - AÑO 2008 - NO 188 \\ EL CINE EN LA PASTORAL DE LAS VOCACIONES, E. LAVANIEGOS Y J. F. COMENDADOR}

etapas que van desde la preparación en la iniciación cristiana hasta la formación permanente. La vocación no es cuestión de un momento en la vida -el de la opción inicial-, sino que supone toda una preparación sin la cual no es posible que el mensaje de la vocación arraigue, y una revisión constante de la propia opción, una respuesta siempre nueva al sí inicial. Por otro lado, si de veras creemos que la vocación es un don de Dios para todos, hemos de estar ciertos de que ésta se hace presente en nuestra vida aunque adquiera una tonalidad diferente a la que imaginamos. El cine, en la medida en que da cuenta de la realidad de la persona, se ha de hacer eco necesariamente del problema vocacional, aunque sea con otros términos y matices. Hemos de estar atentos, pues, para captar cualquier signo de la vocación.

\section{Condiciones para usar una película en la pastoral de las vocaciones}

En la primera parte, nos hemos aproximado al cine como medio de comunicación que puede ser utilizado para comunicar la fe cristiana, y en concreto, el mensaje de la vocación como un elemento fundamental de aquella. Ya hemos visto que es posible transmitir a través de películas ajenas al género religioso valores cristianos, y entre ellos, valores específicamente vocacionales.

No todo tipo de cine es apto para el trabajo catequético-vocacional. No es una cuestión de género: una película fantástica puede comunicar rasgos importantes de la vocación. Se trata más bien de una cuestión de hondura y calidad humana. Toda película presenta una determinada concepción del hombre, una antropología subyacente. En todo filme hay un mensaje de fondo acerca de lo que es el hombre y lo que es esencial para su realización personal. Ese mensaje global es el que es captado, quizá no a nivel lógico-consciente; pero sí a un nivel emocional-subconsciente.

A la hora de escoger una película para el trabajo catequético-vocacional, es importante, por tanto, observar la concepción del ser humano que dicho filme en su conjunto presenta. Hay películas, por ejemplo, que presentan un modelo de ser humano que guía su conducta de acuerdo a valores antivocacionales como el individualismo o el consumismo atroz. Pueden resultar de interés para ilustrar otra temática, pero difícilmente servirán para promover un mensaje relacionado con la vocación.

Las películas de la saga El Padrino (Francis Ford Coppola, 1972), especialmente la I y la III, contienen escenas muy interesantes, con diálogos profundos, en torno a las opciones que el protagonista, Michael 
Corleone (Al Pacino), va tomando. El joven Michael soñaba con un futuro prometedor en la política, pero las circunstancias hacen que acabe inmerso en el sucio juego de la mafia. La vida le brinda ocasiones para recapacitar y reorientar la dirección de su existencia, pero, como víctima de un destino cruel, es incapaz de renunciar a su estilo de vida y retomar el vuelo. La película transmite, así, un mensaje pesimista en torno a la capacidad del hombre de realizar sus sueños y proyectos, quien siempre será vapuleado por las circunstancias. Aunque el guión ofrece buenos diálogos donde de forma implícita se plantea la cuestión de la vocación, la visión del hombre que presenta en su conjunto es bastante desesperanzadora.

Exceptuando las hagiografías, donde es probable que se narre la experiencia vocacional del protagonista -pensemos, por ejemplo, en las películas sobre la vida de Juan Pablo II que se han hecho tras su muerte-, en la mayoría de los filmes no suelen aparecer momentos o escenas de carácter vocacional, al menos tal y como en cristiano entendemos la vocación. ¿Qué criterios, entonces, hemos de tener en cuenta a la hora de usar una película en la catequesis vocacional? Proponemos los siguientes:

* Que el personaje esté abierto a la posibilidad de un llamado externo a él. Que se deje tocar por las circunstancias, tanto personales como sociales. Que experimente la realidad circundante como desafío, como interrogante que plantea una respuesta personal.

* Que no excluya expresamente la trascendencia. El lenguaje cinematográfico tiene una deuda pendiente con la divinidad o lo trascendente. El cine ha logrado expresar los grandes problemas de la existencia humana, pero no ha encontrado la manera de dar cuenta de la dimensión religiosa de la existencia, elemento crucial para muchas personas. Pocas películas se atreven a expresar la relación que un hombre puede establecer con lo trascendente, por eso difícilmente encontraremos reflejado en un filme la posibilidad del llamado divino. Esto no significa que no haya rasgos en algunos guiones que apunten en esta dirección.

* Que se produzca cierto cambio en el personaje principal. Que se constate un proceso de crecimiento o madurez en algún aspecto de la vida del personaje.

* Que el personaje encarne o llegue a encarnar a lo largo de la trama valores vocacionales importantes, como la gratuidad, la servicialidad, la solidaridad, la entrega, etc. 


\section{SEMINARIOS - AÑO 2008 - NO 188 \\ EL CINE EN LA PASTORAL DE LAS VOCACIONES, \\ E. LAVANIEGOS Y J. F. COMENDADOR}

\section{Dos géneros vocacionales}

Los críticos de cine acostumbran clasificar las películas según géneros cinematográficos. Así, se habla de drama, comedia, ficción, terror, cine bélico, cine de aventuras, etc. En este apartado queremos postular dos tipos de películas que, por su contenido argumental, bien merecen ser incluidas en un género que podríamos denominar vocacional.

\subsection{Género vocacional épico}

Se trata de películas de carácter épico que sitúan a un personaje, real o inventado, en un preciso contexto histórico, presentando una evolución personal del mismo a lo largo de la trama. Tales películas reúnen las siguientes características:

- Tiene como protagonista absoluto un personaje alrededor del cual gira toda la trama.

- El protagonista experimenta un proceso de conversión que tiene por objeto adquirir una nueva identidad.

- Dicha conversión tiene lugar a través de un proceso de iniciación que comprende tres momentos: ruptura con la situación previa / conocimiento y aprendizaje de un nuevo estilo de vida / reinserción en la comunidad de origen con una nueva o renovada identidad. Como toda iniciación, este proceso viene marcado por unos ritos de paso que son significativos para el protagonista.

- La conversión y los roles ejercidos conllevan un gran sentido de servicio y generosidad. Hay una comprensión de la propia vida como entrega gratuita a los demás que puede llevar incluso a la muerte.

Un ejemplo -la película El último Samurai- puede ayudarnos a entender mejor los elementos enunciados, que en el caso de esta película se vislumbran claramente. Toda la trama gira en torno al capitán Algren, quien se somete a un proceso de iniciación (ruptura con su pasado, aprendizaje de nuevos valores y costumbres, nueva identidad como samurai) que supone una conversión profunda. Este proceso viene marcado por ritos de paso que van reafirmando su nueva identidad; el más importante es sin duda la investidura con la armadura que perteneció al samurai que mató en el momento en que lo apresaron. Ser samurai significa servir y de hecho así comprenden su existencia. Los samurais sirven hasta dar la propia vida: son capaces de 
morir por aquello en lo que creen. Así es el caso de Katsumoto, líder de este grupo de guerreros.

Hay tres características de la vocación cristiana que nos permiten calificar a estas películas de vocacionales:

- La vocación otorga a la persona una identidad profunda: uno es uno mismo en la medida en que descubre, reconoce y asume la misión a la que ha sido llamado.

- La vocación afecta decididamente a la personalidad: el propio desarrollo personal se entiende en función de la vocación recibida. Por eso la conversión -el cambio personal y profundo- es un elemento necesario y parejo a la vivencia de la propia vocación.

- Toda vocación, sea cual sea, conlleva grandes dosis de servicio. La servicialidad es una nota típicamente vocacional que adquiere múltiples formas.

En la medida en que una película muestra estas realidades podemos calificarla de vocacional. Por lo general, se trata de películas de tintes épicos que narran grandes hazañas. Así, podemos pensar en títulos como Braveheart (Mel Gibson, 1995), El Patriota (Roland Emmerich, 2000), Leyendas de Pasión (Edgard Zwick, 1994), Bailando con Lobos (Kevin Costner, 1990), El Señor de los Anillos (Peter Jackson, 2001), Las Crónicas de Narnia (Andrew Adamson, 2005), etc.

\subsection{Género vocacional contemporáneo}

Si los títulos anteriores se caracterizaban por su tinte épico y por estar enmarcadas en escenarios históricos - el Japón decimonónico de El último Samurai (Edgard Zwick, 2003) o la guerra de secesión estadounidense de El Patriota- o imaginarios -el Señor de los Anillos o las Crónicas de Narnia-, en este subgénero englobamos aquellos títulos que, reuniendo unas características parecidas, se sitúan en un contexto cultural e histórico contemporáneo, marcado por un profundo realismo y verosimilitud. Las características de este tipo de películas son las siguientes:

- La trama gira en torno a un personaje principal al que se describe condicionado por unas circunstancias personales, familiares, laborales o sociales muy concretas.

- En algún momento de la trama surge un reto en forma de desafío, de llamado procedente del exterior de la persona -que adquiere la fisonomía de una misión específica- o del interior de la misma -tomando la forma de un sueño, ilusión o proyecto personal-. 


\section{SEMINARIOS - AÑO 2008 - NO 188 \\ EL CINE EN LA PASTORAL DE LAS VOCACIONES, E. LAVANIEGOS Y J. F. COMENDADOR}

- El personaje se ve abocado a superar obstáculos de diverso tipo -sobre todo la incomprensión por parte de personas significativas- en orden a realizar su misión o conseguir su sueño.

- Finalmente, el personaje alcanza la meta demostrando a los que inicialmente se oponían a su proyecto que merece la pena perseguir lo que se anhela o desea. Se ha producido un caso de superación personal.

De nuevo, un ejemplo concreto -Erin Brockovich (Steven Soderbergh, 2000)- puede servirnos para ilustrar estos elementos. Erin es una joven madre, divorciada, con tres hijos pequeños a su cargo, sin trabajo y con veinticuatro dólares en la cuenta bancaria. Desesperada, acude a su abogado en busca de un trabajo como secretaria. Una vez en el bufete, comienza a indagar en un caso archivado que compromete a una potente compañía de productos químicos. A pesar de su escaso conocimiento de leyes, su tenacidad y cercanía con los afectados hace que el caso sea llevado de nuevo a los tribunales, esta vez con pruebas concluyentes que evidencian la culpabilidad de la empresa. Sus circunstancias personales - desesperada y sin dinero-, familiares - madre soltera-, y laborales - sin trabajoaparecen muy bien definidas en el filme. Erin interpreta este caso como una misión ineludible: si ella no ayuda a los damnificados, éstos no obtendrán ayuda de ninguna otra persona. Para acometer tal misión ha de superar múltiples obstáculos -su desconocimiento del sistema legal, su posición de secretaria, la lejanía respecto a sus hijos, los problemas con su novio, quien se hace cargo de los niños mientras Erin visita a los damnificados, etc.-. Finalmente, Erin consigue su propósito sintiéndose feliz por el resultado obtenido y por haber encontrado un sentido a su vida.

Como en el caso anterior, también aquí podemos hablar de algunas características de la vocación cristiana que nos permiten calificar a estas películas de vocacionales:

- La vocación no sobreviene a las personas como un meteorito, sino que se hace audible en las circunstancias personales y sociales en las que uno está inmerso.

- La vocación cristiana nunca se entiende como un fin en sí mismo, sino como un llamado para una misión específica. Hay una profunda relación entre vocación y misión que impide comprender aquella como un asunto exclusivamente personal.

- La vocación pone en funcionamiento todos nuestros dinamismos, capacidades y cualidades en beneficio de la misión encomendada. 
Cuando uno descubre su vocación pone toda su persona al servicio de la misma. Podemos decir que la vocación, lejos de apocarnos, demanda lo mejor de nosotros mismos, haciendo que nos superemos constantemente.

- El camino vocacional no es un camino de rosas. Recorrerlo conlleva rupturas, asumir nuevas exigencias y desafíos, superar obstáculos. Una presentación triunfalista de la vocación olvida el mensaje evangélico de la cruz, ligado siempre a cualquier proyecto de vida cristiana.

Algunos títulos que reúnen estas características son Billy Elliot (Stephen Daldry, 2000), En Busca de la Felicidad (Gabrielle Muccino, 2006), Million dollar baby (Clint Eastwood, 2004), etc.

Nos atrevemos a denominar a estas películas como vocacionales -tanto las épicas como las contemporáneas- en la medida en que presentan rasgos esenciales de la vocación cristiana. No lo hacen de un modo explícito, pero se observan con facilidad. Evidentemente, estos filmes no presentan una definición completa de la vocación cristiana, sino sólo algunos elementos fundamentales de la misma. La tarea -y la destreza pedagógica- del animador vocacional consiste precisamente en proponer los elementos restantes partiendo siempre del diálogo que se establece entre la película y los destinatarios, es decir, sobre la base de estos otros rasgos de la vocación que sí son apreciables en la película.

\section{Tres propuestas para utilizar el cine en la pastoral de las vocaciones}

Si queremos utilizar el lenguaje cinematográfico de la cultura actual, lo podemos hacer de varios modos. Se trata, en concreto, de tres. A continuación ofrecemos algunas indicaciones para cada unas de estas formas, pero antes es preciso realizar algunas advertencias:

- Estos tres modos de utilizar una película en la catequesis vocacional son, por decirlo así, esquemas de trabajo que han de ser completados por el animador en cada caso concreto. La base del trabajo catequético radica en el diálogo que se establece entre el filme y el espectador, por lo que es desde ese diálogo desde el que ha de articularse la catequesis vocacional.

- A la hora de utilizar una película con un fin catequético es necesario precisar el tema que se quiere abordar, pues el mensaje de la película puede ser susceptible de las más variadas interpretaciones. Por ejemplo: es fácil que la película Mar adentro (Alejandro Amenábar, 


\section{SEMINARIOS - AÑO 2008 - NO 188 \\ EL CINE EN LA PASTORAL DE LAS VOCACIONES, E. LAVANIEGOS Y J. F. COMENDADOR}

2004) dé pie a un diálogo amplio en torno a la eutanasia. Desde una perspectiva vocacional, sin embargo, puede ser utilizada para profundizar sobre la cuestión del sentido de la vida.

- Aunque solamente nos interese un aspecto de la trama, el animador ha de conocer el mensaje global de la película, prever las posibles interpretaciones y estar preparado para responder los interrogantes que puedan surgir tras la visión de una película o escena. Esto supone, en el caso de que se visione solamente una escena, que el animador ha visto la película entera y se ha informado sobre la misma, tanto a nivel técnico como de contenido.

\subsection{El cine foro clásico}

El modo más clásico de hacer el cine foro es sujetándose al relato. Es la típica forma de usar el cine para transmitir un contenido de fe o la postura de la Iglesia sobre algún tema de actualidad (el aborto, la eutanasia, la pena de muerte, etc.). Normalmente hemos utilizado este medio pastoral durante convivencias o jornadas de reflexión, o sea, cuando hemos dispuesto del tiempo necesario para visionar una película y comentarla después.

Hoy en día el DVD y los programas informáticos nos permiten ahorrar tiempo en la visión de una película seleccionando las escenas principales y presentándolas de tal forma que se salvaguarde el relato en sus partes esenciales. Al utilizar las películas con este fin pastoral conviene seleccionar bien las escenas que tendrían que ser visionadas para cumplir dicho objetivo. De todas formas, se recomienda la visión total de la película.

Para hacer este tipo de cine foro es importante que la película tenga por sí misma un contenido vocacional. Las películas que hemos incluido en los géneros vocacionales épico y contemporáneo son las que mejor encajan en esta metodología, pues su mensaje es, a pesar de las deficiencias, eminentemente vocacional. Aparte de las indicaciones sugeridas para cada película que, como hemos dicho, han de ser adaptadas a los destinatarios concretos, es importante que el animador, antes de utilizar la película en cuestión en la catequesis, haya identificado los rasgos vocacionales que en ella aparecen y que han sido descritos en el apartado anterior (conversión, iniciación, valores vocacionales que vive el protagonista, misión, etc.) 


\subsection{La escena vocacional}

El segundo modo de utilizar el cine consiste en la selección de una o dos escenas que son especialmente significativas porque abordan directamente una cuestión relacionada con la vocación. De vez en cuando, el cine nos brinda la oportunidad de contemplar con amabilidad y respeto (a veces incluso con humor) situaciones por las que atraviesan comúnmente las personas vocacionadas. Un caso paradigmático de este uso es la escena de la película Más que amigos (Edgard Norton, 2000), en la que un sacerdote comparte con su director espiritual la crisis que está atravesando.

En este caso los participantes no van a captar la trama general.

Simplemente verán una escena que transmite un mensaje. El mensaje en este caso debe ser lo suficientemente explícito como para que sea bien comprendido e interpretado por todos. Para garantizar esto se puede poner a los participantes en el contexto por medio de un guión escrito, a modo de introducción. También puede prescindirse del contexto, dejando que la escena hable por sí misma, y abriéndose a las interpretaciones variadas que los espectadores propongan.

A la hora de seleccionar estas escenas hay que tener presente la sensibilidad del auditorio, el grado de motivación y conocimiento de la cuestión por parte de los participantes, el nivel de confianza que se da entre los miembros del grupo. No es lo mismo utilizar la citada escena de Más que amigos con un grupo de sacerdotes que con un grupo de adolescentes. Mientras que con los primeros la escena puede resultar muy provechosa, en la medida en que plantea un tema de actualidad e interés personal, para los segundos puede resultar contraproducente, en la medida en que contribuye a aumentar los prejuicios en torno a la vocación con afirmaciones del tipo: ; Ya decía yo que eso del celibato...!

Otro ejemplo de escena vocacional es Tomates verdes fritos (Jon Avnet, 1992). Se trata de una escena en la que Evelin Couch (Kathy Bates) y Ninny (Jessica Tandy) dialogan sobre el fenómeno del cambio a la mitad de la vida. Es una escena luminosa que deja entrever la posibilidad de que después de los cuarenta años puede venir la época más hermosa y fecunda de la vida. Esta escena es muy adecuada para tratar el tema del llamado de Dios en la edad intermedia.

\subsection{La escena peregrina}

Aún podemos poner en práctica un tercer modo. Aquí se selecciona una o varias escenas que aparentemente no tienen un contenido importante en 


\section{SEMINARIOS - AÑO 2008 - NO 188 \\ EL CINE EN LA PASTORAL DE LAS VOCACIONES, E. LAVANIEGOS Y J. F. COMENDADOR}

relación con el tema que se quiere abordar. Por esta razón las llamamos escenas peregrinas, ocasionales, que, precisamente por su aparente desconexión con el tema a tratar, nos introducen de un modo inesperado en el mismo. Se puede tratar de escenas cómicas o misteriosas, más bien ligeras.

Lo que más nos interesa es que la contemplación de estas escenas suscite en los participantes una experiencia, que luego podremos utilizar en la catequesis. Todo método catequético parte de una experiencia comprensible para el destinatario, para desde ahí proponer el mensaje que se quiere transmitir. Se trata, por tanto, de integrar la escena en cuestión como una parte de la metodología catequética, en concreto como introducción.

Así, por ejemplo, la comedia Mi gran boda griega (Joel Zwick, 2002) , que aborda el choque entre la cultura griega y la norteamericana, nos puede servir para plantear el valor de la interculturalidad en el seno de las comunidades de vida. En una casa de formación integrada por miembros procedentes de diversas culturas y países es fácil que se den conflictos. La escena nos ayuda a plantear esta cuestión con grandes dosis de humor. Otro ejemplo: la película Cincuenta primeras citas (Peter Segal, 2004), en la que un joven a de enamorar a su novia cada vez que la encuentra, debido a que la muchacha olvida cada noche lo que ha hecho el día anterior, nos sirve para introducirnos al tema de la fidelidad en la vocación recibida, cuyo éxito no depende de la respuesta inicial, sino que cada día se ha de responder al llamado de un modo renovado y creativo.

Las posibilidades que brinda esta metodología son amplias y dispares. Depende en gran medida de la destreza del animador para conectar la experiencia narrada en la escena con el tema que se quiere abordar. De nuevo, hay que tener en cuenta a los destinatarios y sus particulares características. Los dos ejemplos propuestos no parecen adecuados para un grupo de adolescentes; sí en cambio para un grupo de formandos o de consagrados jóvenes.

A partir de todos los ejemplos mencionados, se puede concluir que el cine es un medio privilegiado de evangelización en el campo de la pastoral de las vocaciones que la tecnología del DVD ha puesto en las manos de los agentes vocacionales para ser utilizado con mucha agilidad. Por un lado ayuda a utilizar un lenguaje más cercano a las personas a quienes nos dirigimos y a la cultura de la imagen y el sonido, pero por otro lado concreta de un modo realista y eficaz la catequesis vocacional. 


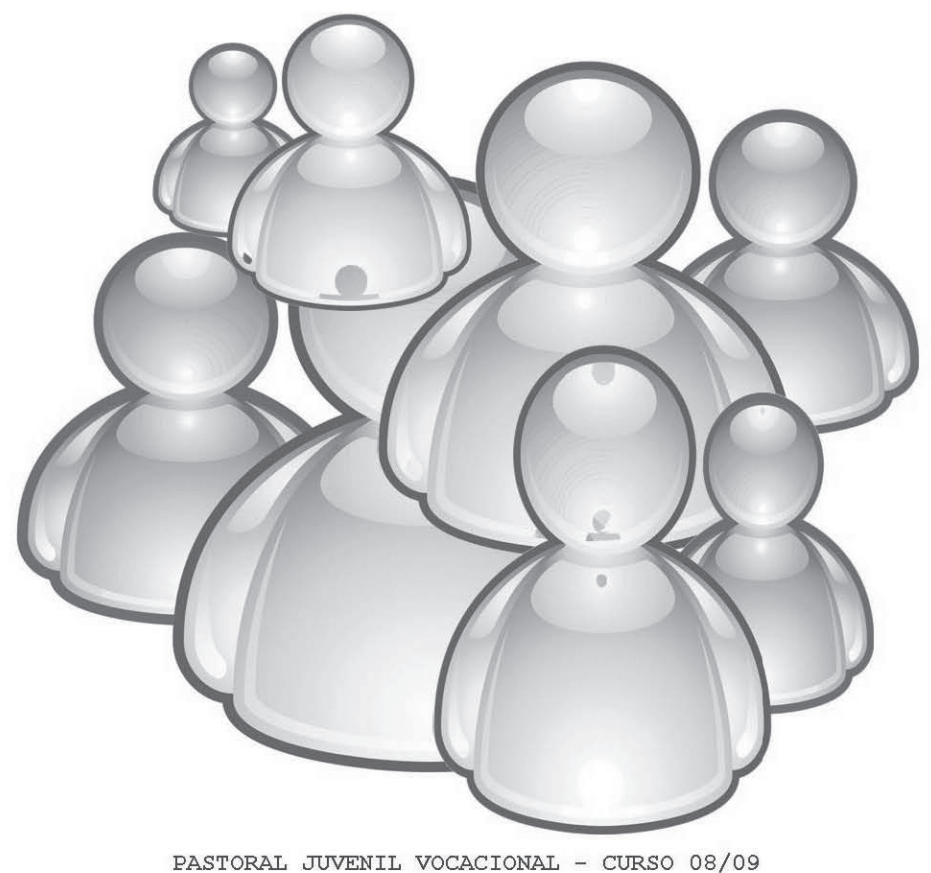

